\title{
Property price and proximity to paper mill: a hedonic pricing analysis of Cachar Paper Mill
}

\author{
${ }^{1}$ Sujoy Das, ${ }^{2}$ Niranjan Roy \\ Ph. D. Research Scholar Department of Economics Assam University, Silchar PIN: 788011 \\ Professor, Department of Economics Assam University, Silchar ,PIN: 788011
}

\begin{abstract}
There are many empirical studies which demonstrated that house price is negatively related to environmental bad such as air pollution, noise, odour etc. However, dealing with industrial impact on house price we should take care of two opposite impacts i.e. positive and negative impact of industry. From the point of view of positive impact, industry provides employment both for the local and the outsider. There are number of out comers desire to stay in the region either for doing job in the industry or absorbing benefit from the built market. But what will happen in case when industry generates pollution as a by-product? In the blend of positive and negative impact of industry, the present study seeks to find out the impact of Cachar Paper Mill $(C P M)$ on property value of the region. Applying Hedonic regression analysis the study found that CPM negatively affects rent of houses which are very closer to it however it has some positive impact on rent of houses which are closer to optimum distance from the mill.
\end{abstract}

\section{Introduction}

A set of studies confirmed that environmental attributes disturb house price. Implication of this is that people impute a definite dissatisfactory value to the poor environmental quality for poor environment or pollution is associated with several health symptoms. But what happens to property value (price of house) when an industry is set up in a region? Because dealing with industrial impact on house price we should care of two opposite impacts i.e. positive and negative impact of industry ${ }^{1}$. From the point of view of positive impact, industry provides employment. Not only local people get the scope of employment but also people from outside region also get this benefit. In secondary flow industry strengthens and extends the local market. This is such that due to industry, there is influx of population in terms of employees from outside region in the industrial region. This raises demand for goods and services and in this way industry creates a good business environment. Another important impact of the increasing population due to industrial set up can be diagnosed in terms of increasing house price. There are number of out comers desire to stay in the region either for doing job in the industry or absorbing benefit from the built market. But what does happen in case when industry generates pollution as a by-product? Don't the house purchasers value environmental non-attributes? Thus we can only hypothesis this since industry is one of the recognised sources of environmental pollution. Employment motive raises the demand for staying close to industrial site, where as environmental quality contracts the propensity to stay near industrial site. This is how industry emits many toxic pollutants in the air. Moreover, there prevails odorous smell in industrial location. Apart from this industrial location is also associated with dust, poor visibility, noise etc. Availability of toxic pollutants is prone to many diseases starting from headache to cancer. These negative attributes act as lowering demand of housing in the region.

In the blend of positive and negative impact of industry, the present study seeks to find out the impact of Cachar Paper Mill (CPM) on property value of the region. The study has its significance as it would expose peoples' preference of choosing a location which maximise their utility. A negative impact on house price would mean peoples' annoyance for environmental pollution. As pollution affects development impact of an industry, it is always suggestive to keep pollution level at the tolerance limit.

\section{Envronmental Attributes and Property Value: Review of Empirical Findings}

There are many empirical studies which demonstrated that house price is negatively related to environmental bad such as air pollution, noise, odour etc. Beron, Murdoch and Thayer (2001) in their study examined the impact of a specific aspect of air quality- visibility, or the ability to clearly see distant objects- on housing values. Their analysis was based on a data set constructed by matching residential housing sales data for the Los Angles metropolitan area for the period 1980 through 1995 with visibility and other characteristics.

\footnotetext{
${ }^{1}$ While we consider negative impact of industry we assume industry is emitting hazardous chemical or other types of pollutants inhalation of which is injurious to health. Industry which adopts completely environmental fresh technology and industries which is free of environmental pollution are beyond our discussion.
} 
The study found that visibility differences were capitalised into housing values, producing a measurable hedonic price gradient.

Parikh et al (1994) has estimated the hedonic property price equation to find out the effects of air pollution on property value in Mumbai. They measured air quality in terms of suspended particulate matter (SPM). The result found that air pollution affects the rent negatively. As the concentration of SPM increases the house price falls.

However to find out industrial impact on house price one problem might have to face that data of various air pollutants are not easy to collect point basis. There are a few studies which used distance as proxy of pollution. For example, Deaton and Hoehn (2004) used distance from hazardous waste site as a proxy of pollution, Flower and Ragas (1994) for oil refinery, Michacles and Smith (1990) for hazardous landfills, Saphores and Benetez (1994) for smelly local polluters.

Saphores and Benitez (2005) evaluated the impact of local industrial odours on surrounding residential houses for four southern Calfornia cities. They flagged houses located at various distances from car point shops and smelly polluters. After accounting for heteroscadasticity through feasible GLS, authors found a statistically significant negative relationship between house prices and smelly pollutants.

Hanna (2007) analysed the effect of polluting manufacturing facilities on the economic characteristics of nearby neighbourhoods. It tested the hypothesis that communities exposed to high levels of pollution would have lower house prices and poorer residents than cleaner locations. The econometric model treated pollution and income as simultaneously determined variables. Author used multiple equation, fixed effect model to account for cross section and time varying biases. The study used toxics released inventory (TRI) and census data from 1980s for the six New-England states. The estimates of the study suggested that being a mile closer to a polluting manufacturing plant reduces house values by $1.9 \%$.

Therefore, we have found from the above distance based studies that house price is positively related to distance from a polluting source. However, this is not clear to what extent distant reflects positive relationship with polluting source. In underdeveloped region where there is immense unemployment, this positive relationship between property value and distance from polluting source seems to be weaker. This depends on peoples' preference for a location considering severity of pollution and positive spread effect of industry.

A Theoretical Issue

\section{Individuals' Preference in Choosing a Location}

While choosing a location individual is guided by many factors or attributes such as availability of market, school, bank, post-office, hospital or nursing home, transport \& communication, crime factor etc. Apart from these factors environment also plays a significant role in individual utility function.

Suppose, an individual wants to purchase a house from two alternative locations A and B. while A and $\mathrm{B}$ have same attributes. The only difference between these two locations is that in location B, a large scale industry has been built up. The result of the establishment of that industry local market soars up.

Individual wants to either maximise his profit or minimise his cost. If he locates at $\mathrm{B}$, he maximises his income. But environmental cost of such a move is positive. Now, consider location A which is far away from B. At location ' $A$ ' opportunity cost of losing income is higher, but then environmental cost is zero. Therefore, the person has two extreme locations roughly featured by income and costs differentials. Now, what is the feature of mid-places between A and B? If the individual moves forward towards location A, opportunity cost will continually fall and environmental cost will continually rise. Here we will resort to some assumptions to give a logical stand.

\section{Assumptions:}

1. Hypothetical individual wants to maximise his gain or minimise his cost.

2. There is no possibility of moving from one location to another location to capture benefit.

3. Environment cost is positive in location B and it falls continually when he moves away from B to A.

4. Location $B$ has higher income earning scope and this scope comes down continually as the person moves from location B towards A, and vanishes at location A.

Now question comes forth, where does our rational individual would prefer to locate? He faced with a trade off between income and environmental cost. In one side he wants to maximise his income. But this involves high environmental cost. Ideal location for individual will be where his total cost is minimum. Let us explain the simplified system with the help of table 1 where opportunity cost of locating away from industry and environmental cost of living closer to industry is presented with varying distance from industry. 
Table 1: Hypothetical Presentation of Opportunity Cost and Environmental Cost with Varying Distance from Industrial Set-up.

\begin{tabular}{|c|c|c|c|}
\hline Distance (k.M.) & Opportunity cost & Environmental cost/ Health cost & Total cost \\
\hline 1 & 0 & 500 & 500 \\
\hline 2 & 150 & 350 & 500 \\
\hline 3 & 175 & 300 & 475 \\
\hline 4 & 250 & 200 & \\
\hline 5 & & & \\
\hline 6 & 400 & 80 & 50 \\
\hline
\end{tabular}

We can see the opportunity cost is zero at distance 1 K.M. from industry. Opportunity cost increases as distance from industry increases. This is because spread effect of industry gets weaker while moving away from industry. On the otherhand, we assumed industry emerges toxic pollutants which impairs health. Therefore, at distance 1 K.M. (d1) environmental cost is highest and it continually falls as distance from industry increases and at a certain distance (say 5 K.M.) this cost disappears. It will be profitable for the concerned individual if he choose such location which minimises his total cost, i.e., cost of losing income if one stays at centre and environmental cost. The fourth column of the table shows that at distance 4 K.M. total cost is minimum. Therefore, a rational individual will locate at a distance of 4 K.M. from industry.

To put this in different fashion we assume opportunity cost increases at a rate ' $r$ ' at each successive distances where at distance 1 K.M. ' $r$ ' is kept zero. Therefore, at distance d opportunity $\operatorname{cost}\left(\mathrm{C}_{\mathrm{opp}}\right)$ will be :

$\mathrm{C}_{\text {opp }}=(\mathrm{d}-1) \mathrm{r}$, where $\mathrm{d}=1,2,3, \ldots, \mathrm{n}$.

Now again we assume, environmental cost or health cost decreases at a rate ' $h$ ' in each successive distance where at distance $n$ ' $h$ ' is kept zero showing zero environmental cost. Then, environmental cost or health cost in distance $d$ will be as follows:

$$
\mathrm{C}_{\text {env }}=(\mathrm{n}-\mathrm{d}) \mathrm{h} \text {, where } \mathrm{d}=1,2,3 \text {, }
$$
written as:

If we add opportunity cost and environmental cost we find total cost at each distance. This can be

$$
\begin{aligned}
\mathrm{C} & =\mathrm{C}_{\text {opp }}+\mathrm{C}_{\text {env }} \\
& =(\mathrm{d}-1) \mathrm{r}+(\mathrm{n}-\mathrm{d}) \mathrm{h}
\end{aligned}
$$

Total cost $\mathrm{C}$ at initial distance $\mathrm{d} 1$ is very high as revealed by table 1 due to excessive environmental cost. However, $\mathrm{C}$ starts declining at successive distances till a point after that $\mathrm{C}$ again moves upward due to increasing opportunity cost. This gives a $\mathrm{U}$ shaped cost curve.

Thus in quadratic form we express our cost function as: $\mathrm{C}=(\mathrm{d}-1)^{2} \mathrm{r}+(\mathrm{n}-\mathrm{d})^{2} \mathrm{~h}+(\mathrm{d}-1) \mathrm{r}+(\mathrm{n}-\mathrm{d}) \mathrm{h}$

To find out optimum distance to locate we differentiate $\mathrm{C}$ with $\mathrm{d}$ and setting it equal to zero we find:

$$
\begin{aligned}
\frac{d C}{d d} & =2(\mathrm{~d}-1) \mathrm{r}-2(\mathrm{n}-\mathrm{d}) \mathrm{h}+\mathrm{r}-\mathrm{h}=0 \\
& \Rightarrow \mathrm{d}=\frac{(r+2 n h+h)}{2(r+h)} \ldots \ldots \ldots \ldots \ldots \ldots \ldots \ldots \ldots \ldots \ldots \ldots \ldots \ldots \ldots \ldots \ldots \ldots
\end{aligned}
$$

However, an individual will prefer to locate within the distance of 1 K.M. from industry if we suppose environmental cost is zero. Because, then he can maximise his income benefit.

Now let us introduce rent as a function of economic development or economic benefit of industrial set up or positive income impact of industry and environmental cost.

$\operatorname{Rent}(\mathrm{R})=\mathrm{f}($ economic development $(\mathrm{ED})$, environmental $\operatorname{cost}(\mathrm{E}))$

$$
\text { Such that, } \frac{d R}{d E D}>0 \text { and } \frac{d R}{d E}<0
$$

Implication of this is that rent is positively related with economic development of industrial set up. The second case indicates a negative relationship between rent and environmental pollution. Environmental pollution is one sorts of negative attribute. Hence it affect house price negatively.

Alternatively we can also say that rent is function of cost i.e. opportunity cost of loosing income and environmental cost such as:

$$
\begin{aligned}
& \mathrm{R}=\mathrm{f}(\operatorname{Cost}(\mathrm{C}))=\mathrm{f}\left(\mathrm{C}_{\text {opp }}, \mathrm{C}_{\text {env }}\right) \\
& \text { Let us write Rent function as... }
\end{aligned}
$$

$\mathrm{R}=\mathrm{a}-\beta \mathrm{C}$

$\mathrm{R}=\mathrm{a}-\beta[(\mathrm{d}-1) \mathrm{r}+(\mathrm{n}-\mathrm{d}) \mathrm{h}]$ (from equation 3)

$\frac{d R}{d d}=-\beta \mathrm{r}+\beta \mathrm{h}$

From equation (8) we can not say $\frac{d R}{d d}>/<0$; if $\mathrm{h}>\mathrm{r}$ then $\frac{d R}{d d}>0$ and vice versa.

If however cost function is in quadratic form then,

From equation (4) and (7), we write,

$\mathrm{R}=\mathrm{a}-\beta\left[(\mathrm{d}-1)^{2} \mathrm{r}+(\mathrm{n}-\mathrm{d})^{2} \mathrm{~h}+(\mathrm{d}-1) \mathrm{r}+(\mathrm{n}-\mathrm{d}) \mathrm{h}\right]$ 
Now,

$\frac{d R}{d d}=-2 \beta(\mathrm{d}-1) \mathrm{r}+2 \beta(\mathrm{n}-\mathrm{d}) \mathrm{h}-\beta \mathrm{r}+\beta \mathrm{h}$.

Again looking at equation (10) we can not clearly say that $\frac{d R}{d d}$ is greater than zero or less than zero. Thus in our forthcoming section using an empirical data we will test the relationship of rent with distance from CPM.

\section{Study Area and Data:}

Study Area: Cachar Paper Mill is located at Panchgram and in the district of Hailakandi. It is one of the few large scale industrial undertakings of Barak Valley and in the North Eastern part of India, particularly the Southern part of North East region covering Tripura, Mizoram, Manipur, and Meghalaya \& Southern Assam .The mill has started its production in 1988. The main raw material of paper production is bamboo. Despite lack of infrastructural support, CPM has a continuous record of steady improvement for a series of years. During the year 2006-07, the mill recorded the highest annual production of 1,03,155 MT after utilizing $103 \%$ of its capacity. The mill is situated at the bank of river Barak. The mill also generates a good number of employments in the tiny sector in the economy of Barak Valley.

Data: The study is based on primary survey. As a first step of data collection we have chosen certain locations which maintain consecutively increasing distance from CPM. The chosen locations are: Panchgram, Thandapur, Bokhrihawor, Uttar kanchanpur, Kathakhal and Salchapra. In the second step we have identified rental houses of each location. Then out of these rental houses, using random sampling method and Yammne's sampling size determination technique (1970) we have selected 200 rental houses for intensive study. The basic characteristics of these locations are more or less homogeneous. Only visible difference is that there is a paper mill near Panchgram and Uttar Kanchonpur. Uttar Kanchonpur has the shortest distance from CPM.

\section{Methodology}

To find out impact of Cachar Paper Mill on property value we have resorted to hedonic pricing method (Rosen, 1974). The hedonic pricing approach derives from the characteristics theory of value first proposed by Lancaster(1966) and Rosen (1974). This seeks to explain the value of a commodity as a bundle of valuable characteristics where one or more of these characteristics may be environmental (Hanley, Shogren and White,1997 ). In order to estimate a hedonic price function, it is necessary to gather data on house sale prices and all characteristics of those houses thought relevant to their value (Hanley, Shogren and White, 1997). For a house, relevant characteristics include structural features (such as number of rooms, bathrooms, square footage), neighbourhood characteristics (crime, distance to supermarket etc.), location (e.g. distance to the ocean) and environmental quality (Saphores and Benitez 2005). For the present study we have chosen a set of variables considering the characteristics of the region. Distance from CPM is considered as proxy of industrial pollution as well as income impact of industry. The chosen variables for the present study are:

\subsection{The Variables and Model}

Depended Variable: Rents of houses' are treated as depended variable.

\section{Independent Variables:}

Structural variables: house type, number of rooms, average size of room, availability of sanitary latrine, availability of attached bathroom, availability of water facility, availability of electricity.

Neighbourhood variable: distance from market, distance from main road, distance from bank, distance from school, distance from town.

Environmental variable: distance from Cachar Paper Mill.

Other variable: Number of years the household is residing.

The hedonic regression model is given as follows:

$\ln \mathrm{P}=\alpha+\beta 1$ distance from $\mathrm{CPM}+\beta 2(\text { distance from CPM })^{2}+\beta 3$ House type $+\beta 4$ No of Rooms $+\beta 5$

Size $+\beta 6$ sanitary latrine $+\beta 7$ Availability of attached bathroom $+\beta 8$ availability of water facility $+\beta 9$ availability of electricity $+\beta 10$ distance from market $+\beta 11$ distance from Main road $+\beta 12$ distance from Bank $+\beta 13$ distance from town $+\beta 14$ distance from school $+\beta 15$ No of years of residing $+\mathrm{Ui}$

\section{Prevalence of multicolinearity among independent variables:}

Before running the regression equation we have found existence of problem of multicolinearity among variables. Therefore, by using principal component analysis we have built three indices. These are: Housing Infrastructure Index, Housing accommodation Index and Neighbourhood Index. 
Housing Infrastructure Index (HII): we have chosen three variables for determining quality of house type. The variables are, viz, house type (i.e., Katcha or Pucca), no of rooms and size of room. Rent of a house is expected to rise with the rise in housing infrastructure index. The index is formed as follows:

HII = w1House Type + w2 No of Rooms $+w 3$ Size of Room

$\mathrm{W} 1, \mathrm{w} 2$ and $\mathrm{w} 3$ are chosen after accomplishing principal component analysis for these three variables.

Housing Accommodation Index (HAI): this index reflex the status of housing accommodation such as whether the household has sanitary latrine, attach bathroom and water facility. This index is also expected to affect house price positively. The index looks as follows:

HAI = w11 Availability of sanitary latrine + w22 Attach Bathroom + w3 Water Facility

Neighbourhood Index (NI): this index deals with the status of location of the house. The neighbourhood characteristics that we have included are distance from main road, distance from market, distance from bank, distance from educational institute, distance from nearest town. Remoteness of the location from the above mentioned centres is expected to affect house price negatively. However, the affect on house price in a location which is very proximity to road or market is ambiguous as noise like factors in market or road area may create disutility among people residing there. The index is constructed as follows:

$\mathrm{NI}=$ w13 Distance from Main Road + w23 Distance from Market + w33 Distance from Bank + w43 Distance from School + w53 Distance from nearest town.

The value of w's are chosen from principal component analysis and these are given in the table 2.

Table 2: Weight Assigned to Various Attributes by Principal Component Method

\begin{tabular}{|l|l|l|l|}
\hline Index & Variables/components & \multicolumn{2}{|c|}{ Weights/loadings } \\
\hline \multirow{4}{*}{ HII } & House Type & $\mathrm{W} 11$ & 0.695 \\
\cline { 2 - 4 } & Number of rooms & $\mathrm{W} 12$ & 0.631 \\
\cline { 2 - 4 } & Size of the room & $\mathrm{W} 13$ & 0.469 \\
\hline \multirow{4}{*}{ HAI } & Availability of sanitary latrine & $\mathrm{W} 21$ & 0.632 \\
\cline { 2 - 4 } & Attach bathroom & $\mathrm{W} 22$ & 0.733 \\
\cline { 2 - 4 } & Water facility & $\mathrm{W} 23$ & 0.464 \\
\hline \multirow{3}{*}{ NI } & Distance from main road & $\mathrm{W} 31$ & 0.3054 \\
\cline { 2 - 4 } & Distance from market & $\mathrm{W} 32$ & 0.9026 \\
\cline { 2 - 4 } & Distance from bank & $\mathrm{W} 33$ & 0.9021 \\
\cline { 2 - 4 } & Distance from school & $\mathrm{W} 34$ & 0.876 \\
\cline { 2 - 4 } & Distance from nearest town & $\mathrm{W} 35$ & 0.385 \\
\hline
\end{tabular}

The Model: finally we have selected the hedonic model as follows:

$\mathrm{Ln} \mathrm{HP}=\beta_{0}+\beta_{1}$ DISCPM $+\beta_{2}(\mathrm{DISCPM})^{2}+\beta_{3} \mathrm{HII}+\beta_{4} \mathrm{HAI}+\beta_{5} \mathrm{NI}+\mathrm{Ui}$

5.2 Optimum Distance: optimum distance from CPM is the distance from CPM where positive impact of CPM minus negative impact is maximum. In other words at optimum distance house rent should be maximum. We can find out optimum distance from CPM by differentiating the hedonic price function with respect to DISCPM. This is given as below:

$\mathrm{Ln} \mathrm{HP}=\beta_{0}+\beta_{1} \mathrm{DISCPM}+\beta_{2}(\mathrm{DISCPM})^{2}+\beta_{3} \mathrm{HII}+\beta_{4} \mathrm{HAI}+\beta_{5} \mathrm{NI}+\mathrm{Ui}$

Or, $\mathrm{HP}=e^{\beta 0}+\beta 1$ DISCPM $+\beta 2$ (DISCPM) $2+\beta 3 \mathrm{HII}+\beta 4 \mathrm{HAI}+\beta 5 \mathrm{NI}+\mathrm{Ui}$

Now, to find out optimum distance we differentiate HP() with respect to DISCPM and set it equal to zero:

Or, $\delta \mathrm{HP} / \delta \mathrm{DISCPM}=\beta_{1}+2 \beta_{2} \mathrm{DISCPM}=0$

$\Rightarrow \beta_{1}=-2 \beta_{2}$ DISCPM

$\Rightarrow$ DISCPM $=-\beta_{1} / 2 \beta_{2}$

$\Rightarrow$ Optimum distance $=-\beta_{1} / 2 \beta_{2}$

\section{Result and Discussion:}

The result of the present study is subdivided into two sections. In section I distance -wise distribution of rent is analysed and in section II the result of hedonic regression equation is discussed.

\subsection{Distance-wise distribution of rent:}

In this section, we simply plot the mean value of the rent of houses against each distance. This is presented in the table 3 .

Table 3: Distance-wise Distribution of Mean Rent

\begin{tabular}{|l|c|c|c|c|c|c|c|c|}
\hline $\begin{array}{l}\text { Mean } \\
\text { Rent }\end{array}$ & 414.28 & 788.88 & 805.55 & 1036.11 & 1350 & 800 & 864.28 & 500 \\
\hline $\begin{array}{l}\text { Location/Distance } \\
\text { from CPM }\end{array}$ & 0.5 & 1 & 1.5 & 2 & 2.5 & 3 & 4 & 10 \\
\hline
\end{tabular}

Source: Field Survey 2011-12 
Table 3 reveals that mean house rent at very close to CPM is smallest. As the distance moves from 0.5 K.M., toward upward rental value starts increasing. At distance 2.5 K.M. from CPM, the table exhibits the highest average house rent. First implication of distribution of average rent distant-wise is that average value of rent increases while distance from CPM increases. However, rent starts falling after it reaches 3 K.M. away from CPM. The reason that we can explain behind this is that at very close to paper mill, i.e. distance less than 0.5 K.M., negative environmental attributes or pollution is expected to prevail largely. People who live very proximity to a polluting industry have to tolerate many negative attributes such as industrial odour, dust, noise, and other smelly or hazardous chemical emitted by industry. These negative attributes harm peoples' utility and create a downward pressure in housing demand as well as price in such location. Question automatically arises what is the income impact of industry which should drive rent of house upward. First thing is that at very proximity to industry negative attributes persists in such exorbitant rate that it harms development impact too. Employees of industry and other beneficiaries prefer to choose such location which minimises their total cost, i.e., environmental cost and opportunity cost. Therefore, demand of such location which in one side relatively adjacent to industry and in other side environmental impact is at endurable level. That is the reason rent in such location is comparatively higher than the location very proximity to an industry provided that rent is function of cost. It is also revealed from the table (3) that as distance from CPM increases rent also increases. Secondary impact of industry i.e. expansion of other business activities is also higher in such location which generally grows up basing on demand which is readily available at optimum distance from industry. The total impact that is direct income impact and indirect income impact of industry makes the preferred location a business or commercial centre. Due to this development aspect again create an upward pressure on housing demand and hence on rent. Now what is the implication of second finding? That is rent falls beyond a distance which we termed as optimum distance. The spread effect of industry dries up by degrees while moving away from industry and therefore, housing demand also comes down.

\subsection{The Result of Hedonic Regression:}

The analysis of the impact of industry on house rent which is presented in 6.1 will be erroneous until and unless we control other attributes which simultaneously affect house rent. Therefore in this section we will analyse the result of hedonic regression which considers other expected attributes related to house price. Table (4) provides the estimation of the model. While conducting the regression analysis we have detected the problem of heteroscedasticity using White test. Therefore to come out of the problem standard errors have been corrected by using White( 1980) heteroskedasticity-consistent standard errors \& covariance matrix.

Table 4: Result of Hedonic Regression Analysis

\begin{tabular}{|c|c|c|}
\hline Explanatory & \multicolumn{2}{|c|}{ Dependent Variable: $\ln$ HOUSE RENT } \\
\hline & Coefficient & t-stats \\
\hline Constant & 2.33 & $17.5^{*}$ \\
\hline$D I S$ & 0.08 & $2.409^{* *}$ \\
\hline$D I S 2$ & -0.005 & $-1.85^{* *}$ \\
\hline$H I I$ & 0.0029 & $2.28^{* *}$ \\
\hline$H A I$ & 0.218 & $4.11^{*}$ \\
\hline$N I$ & -0.026 & $-2.71^{*}$ \\
\hline$Y R S D N G$ & -0.021 & $-1.81^{* *}$ \\
\hline
\end{tabular}

N.B. 1.The heteroscedasticity bias of standard errors has been corrected by using the White's estimator

$2 *$ indicates significance at $1 \%$ level and $* *$ indicates significance at $5 \%$ level

Let us first see whether coefficient of distance which is a proxy variable of industrial pollution as well as industrial development, is significant or not. It is found from the regression result that coefficient of distance is significant and it is positive implying that house value or rent rises if distance from CPM increases. However, it is also evident from the result that coefficient of square of distance from CPM is also found significant but with negative sign. This implies that after a certain distance which we termed as optimum distance rent of the houses' falls as distance further increases. We can now find out optimum distance by following equation (15) :

Optimum Distance $=-\beta_{1} / 2 \beta_{2}$

$$
\begin{aligned}
& =0.08 / 2(0.005) \\
& =8 \mathrm{~K} . \mathrm{M} .
\end{aligned}
$$

The results of the coefficient of other variables are also found expected and meaningful. We have seen that coefficient of House infrastructure index (HII) is 0.00029. the corresponding ' $t$ ' value is 2.289140 which is significant at 0.05. This ensures that rent increases with the increase in HII. Similarly, the coefficient of Housing Accommodation Index (HAI) is also found significant and positive which indicates that as housing accommodation such as availability of sanitary latrine, attach bathroom and water facility, improves rent of house also improves. 
From the above table (4) we have found that coefficient of Neighbourhood Index (NI) is negative and significant. This implies as the distance from main road, distance from market, distance from bank, distance from educational institute and distance from town increases, house value or rent falls. Further the table reflects that house rent is inversely related with number of years a tenant resides.

\section{Conclusion}

As far as impact of Cachar Paper Mill (CPM) on property value (house rent) of local households is concerned, it is found that CPM has negative impact on house rent if the house is very close to it. But beyond the optimum distance as the distance increases from CPM property value increases and after a certain distance property value starts falling. This implies as the distance increases from CPM environmental pollution goes down, at the same time employment or income impact of industry also comes down with the increase in distance. But the rate of fall in concentration of pollution with the increase in distance is more rapid than the rate of fall in income or employment impact of CPM. Thus people prefer to locate their house at a distance neither too close nor too far from the industry such that their benefit is maximised. In response to this house demand in that distance soars up which follows hike in house price. However, if pollution is kept at minimum possible level then house rent is also supposed to rise for those very close to CPM. Hence, it is suggestive for CPM to control pollution to compensate losses in terms of loss in property value incurred by house owner who are very close to CPM.

\section{References:}

[1]. Beron, K., Murdoch, J., and Thayer, M. (2001), "The benefits of visibility improvement: new evidence from the Los Angeles metropolitan area," Journal of Real Estate Finance and Economics, Vol. 22 , No. 2/3, pp. 319-337.

[2]. Deaton, B. J., and Hoehn, J.P. (2004), "Hedonic analysis of hazardous waste sites in the presence of other urban disamenities," Environmental Science \& Policy, Vol.7 pp. 499-508, www.elseiver.com.

[3]. Benitez, I.A., and Saphores, J.D. (2005), "Smelly local polluters and residential property values: A hedonic analysis of four orange county (Calfornia) cities," Estudios Economicos, Vol.20, No.2, pp. 197 -218.

[4]. Flower, P., and Ragas, W. (1994), "The Effects of Refineries on Neighbourhood Property Values," Journal of Real Estate Research, Vol. 9, No.3, pp. 319-338

[5]. Lancaster, K. (1966), " A New Approach to Consumer Theory, Journal of Political Economy," Vol. 74, No.2, pp.132-157

[6]. Michaels, R.G. and Smith, V.K. (1990), "Market Segmentation and valuing Amenities with Hedonic Models: The Case of Hazardous Waste Sites;" Journal of Urban Economics, Vol.28, pp. 223-242

[7]. Hanna,B.G.(2007), "House Values, Incomes and Industrial Pollution," Journal of Environmental Economics and Management, Vol.54, No.1, pp.100-112.

[8]. Rosen, S. (1974), "Hedonistic Prices and Implicit Markets: product differentiation in pure competition," Journal of Political Economy, Vol.82, No.1, pp. 34-55.

[9]. Hanley, N., Shogren, J.F. and White, B. (1997), "Environmental Economics: in theory and practice," Oxford University Press, Newyork.

[10]. White, H. (1980), " A Heteroskedasticity -consistent Covariance Matrix Estimator and a Direct Test for Heteroskedasticity," Econometrica, Vol.48, No.4, pp: 817 - 838

[11]. Yamane, T.(1967), "Statistics, An Introductory Analysis," 2-nd edition, Harper and Row, Newyork. 